\title{
Understanding the role of miRNAs in the pathogenesis of brain arteriovenous malformations
}

\author{
Ilgiz GAREEV $V^{1, *}$; Ozal BEYLERLI ${ }^{1, *}$; Chunlei WANG ${ }^{2,3}$; ANDReI SOKHATSKII ${ }^{2,3}$; Yanchao LIANG ${ }^{2,3}$; Huan XIANG ${ }^{2,3}$; \\ ChUNYANG LIU ${ }^{2,3}$; XUN XU ${ }^{2,3}$; YANG GUANG ${ }^{2,3, *}$ \\ ${ }^{1}$ Bashkir State Medical University, Ufa, Republic of Bashkortostan, Russia \\ 2 Department of Neurosurgery, the First Affiliated Hospital of Harbin Medical University, Harbin, China \\ ${ }^{3}$ Institute of Brain Science, Harbin Medical University, Harbin, China
}

Key words: Brain arteriovenous malformations, MiRNA, Pathogenesis, Biomarker

\begin{abstract}
Brain arteriovenous malformations (AVMs) are abnormal vessels that are prone to rupture, causing lifethreatening intracerebral hemorrhage (ICH). Understanding the molecular basis of pathogenesis, timely diagnosis, and treatment of brain AVMs are some of the urgent problems in neurosurgery. MicroRNAs (miRNAs) are small endogenous RNAs that regulate gene-expression posttranscriptionally. MiRNAs are involved in almost all biological processes, including cell proliferation, apoptosis, and cell differentiation. Recent studies have shown that miRNAs can be involved in brain AVMs formation and rupture. There are also extracellular forms of miRNAs. Circulating miRNAs have been detected in the blood circulation and other body fluids. Owing to their stability and resistance to endogenous RNase activity, circulating miRNAs have been proposed as diagnostic and prognostic biomarkers for various diseases, such as tumors, cardiovascular and autoimmune diseases. In this review, we summarized the role of some miRNAs in brain AVMs pathogenesis and discussed their potential clinical application as non-invasive biomarkers.
\end{abstract}

\section{Introduction}

Brain arteriovenous malformations (AVMs) are usually regarded as congenital disorders resulting from aberrant differentiation of the mesoderm during embryonic development (Magro and Gentric, 2020). AVMs consist of abnormally developed dilated arteries and veins and are characterized microscopically by the absence of a capillary network (Magro and Gentric, 2020; Zhang et al., 2016). Intracerebral hemorrhage (ICH) is the most severe and most common clinical manifestation of brain AVMs (Zhang et al., 2016). Risk factors associated with rupture of brain AVMs include certain genetic mutations, intranidal aneurysms, deep venous drainage, impaired venous outflow, and infratentorial arrangement of AVMs (Magro and Gentric, 2020; Murthy et al., 2017; Zhang et al., 2016). The average annual brain AVMs rupture rate has been approximately $2-4 \%$ with an incidence of 0.51 per 100,000 per year (Can et al., 2017).

MicroRNAs (miRNAs) are endogenous noncoding RNAs of 18-22 nucleotides (nt) that regulate gene expression at the

\footnotetext{
*Address correspondence to: Yang Guang, yangguang1227@163.com; Ozal Beylerli, obeylerli@mail.ru; Ilgiz Gareev, ilgiz_gareev@mail.ru Received: 23 February 2021; Accepted: 19 April 2021
}

post-transcriptional level through interaction with 3'untranslated regions (3-'UTRs) of the mRNA target (Gareev et al., 2020). The canonical pathway of miRNA biogenesis begins in the cell nucleus with the transcription of the miRNA gene by RNA polymerase II with the formation of primary miRNA (pri-miRNA), often reaching several thousand nucleotides in length and undergoing 5'-capping and, often, 3'-polyadenylation (Fig. 1). Pri-miRNAs have a complex secondary structure with many hairpins, and can additionally form a complex three-dimensional structure, the parameters of which determine the efficiency of recognition and processing by protein factors. At the next step, primicroRNA is hydrolyzed in the nucleus by a microprocessor complex consisting of Drosha class RNase III and DGCR8 protein. Due to its affinity for double-stranded RNA, the microprocessor recognizes hairpins in pri-miRNA that have a characteristic structure and carry certain nucleotide motifs. As a result of hydrolysis, hairpin RNA molecules are released with a length of $\sim 70 \mathrm{nt}$, called precursor miRNAs (premiRNA) and consisting of a loop single-stranded region and a double-stranded stem ending in a protruding 3 '-end $2 \mathrm{nt}$ long. These structural elements are required for recognition by Exportin-5, which, with the participation of the GTPase RanGTP, transfers pre-miRNA into the cytoplasm of the cell. 




FIGURE 1. MiRNAs biogenesis. It has been proven that miRNAs play a significant role in various biological processes, including proliferation, differentiation, and cell apoptosis ( $\mathrm{Lu}$ and Rothenberg, 2018).

In the cytoplasm, pre-miRNA is transferred to a complex of proteins consisting of RNase III class Dicer, transactivation response RNA-binding protein (TRBP), protein kinase $\mathrm{R}$ activating protein (PACT), and one of the proteins of the Argonaute family (AGO1-4). Dicer recognizes the characteristic structure of the pre-miRNA and cuts out a loop region from it. This leads to the formation of asymmetric double-stranded RNA molecules 18-22 nucleotides in length with protruding 3 '-ends 2 nt in size-miRNA duplex. The final stage of the canonical pathway of miRNA biogenesis is the "loading" of one of the duplex strands onto the AGO protein with the formation of RNA-induced silencing complex (RISC). During the loading of microRNA into RISC, miRNA is transferred and bound by the AGO1-4 protein, the leading strand is selected, the miRNA duplex is untwisted, and the second strand is removed. MiRNA in the RISC complex "turns off" the expression of its target genes, and the choice of targets is determined by the miRNA sequence, more precisely, by the presence of a complementary sequence in the mRNA (Correia de Sousa et al., 2019; Gareev et al., 2020; Michlewski and Cáceres, 2019).

Importantly, dysregulation of miRNAs is found to be involved in various diseases, such as vascular anomalies (Tab. 1) (Dai et al., 2018; Fei et al., 2018; Huang et al., 2017a; Cannavicci et al., 2019; Tabruyn et al., 2013;
Xia et al., 2017; Kar et al., 2017; Ferreira et al., 2014b; Ferreira et al., 2014a; Marín-Ramos et al., 2020; Huang et al., 2017b).

Recent studies indicate that miRNAs are involved in the formation and rupture of brain AVMs, which gives us new insights into the pathogenesis of brain AVMs and might lead to the finding of new therapeutic targets. A challenging aspect of brain AVMs monitoring is the lack of reliable biomarkers reflecting the progression of AVMs and the risk of rupture. It is known that miRNAs can be detected in biological fluids, such as blood, in a remarkably stable form. Circulating miRNAs have been reported to exhibit tissueand disease-specific expression in biofluids (Sohel, 2020). Therefore, circulating miRNAs may represent potential noninvasive biomarkers for monitoring the progression and likelihood of rupture of one of the blood vessels in AVMs. Here, we reviewed recent discoveries about how miRNAs are involved in the pathogenesis of brain AVMs and how it can promote the development of new therapies and noninvasive biomarkers.

\section{Molecular Basis of Brain AVM Pathogenesis}

According to some studies, heterozygous loss-of-function mutations in the RAS P21 protein activator 1 (RASA1) gene can cause a pathology such as capillary malformation, which is a recently discovered, familial disorder in which patients have cutaneous capillary malformations, but they can also be located in the brain (Wooderchak-Donahue et al., 2012). Another typical manifestation of this mutation is the presence of a large varix that drains blood from the arteriovenous anastomosis and includes aneurysmal dilatation of the Galen's vein. This phenotype is explained by heterozygous loss-of-function mutations in the RASA1 gene, which encodes a protein that activates p120-Ras GTPase (RasGAP) (Atri et al., 2014). This protein acts to negatively regulate cell growth and proliferation downstream of receptor tyrosine kinases by accelerating the hydrolysis of guanosine triphosphate associated with Ras. Deactivating mutations of GAPs can augment signaling of the RAS oncogene, which is evidenced by mutations of such proteins in basal cell carcinoma and neurofibromatosis. RASA1 mutations also link the pathogenesis of brain AVMs to extracellular signalregulated kinase $(E R K)$ signaling, as $R A S$ is upstream of $E R K$ and diminished $R A S$ deactivation engenders increased $E R K$ activity (Atri et al., 2014; Park et al., 2021).

Published studies show that a significant proportion of juvenile polyposis and hereditary hemorrhagic telangiectasia (JP-HHT) patients develop AVMs of the lung and liver, capillary telangiectasia of the brain, and oral telangiectasia (Gallione et al., 2004). The pathogenesis of JP-HHT might be due to different effects of lowered levels of mothers against decapentaplegic homolog 4 (SMAD4) within endothelial cells, leading to decreased transforming growth factor beta/bone morphogenetic proteins (TGF- $\beta / B M P s)$ signaling, which may produce vascular dysplasia (Atri et al., 2014; Fereydooni et al., 2019). Recent animal models have shown that endothelial loss of SMAD4 mimics the vascular phenotypes seen in other HHT mouse models, especially AVM formation. It has been demonstrated that increased proliferation and size of endothelial cells (ECs), changes in 
TABLE 1

MiRNAs involved in the pathogenesis of vascular anomalies

\begin{tabular}{|c|c|c|c|c|c|c|}
\hline Disease & miRNA & $\begin{array}{l}\text { miRNAs } \\
\text { gulation }\end{array}$ & Targets & $\begin{array}{l}\text { Experimental } \\
\text { model }\end{array}$ & Functions & References \\
\hline Hemangioma & $\operatorname{miR}-494$ & Up & $\begin{array}{l}\text { PTEN/ } \\
\text { PI3K/AKT }\end{array}$ & $\begin{array}{l}\text { In vitro, in } \\
\text { vivo and ex } \\
\text { vivo }\end{array}$ & Promotes ECs proliferation & $\begin{array}{l}\text { Dai et al., } \\
2018\end{array}$ \\
\hline Hemangioma & miR-424 & Up & VEGFR-2 & Ex vivo & $\begin{array}{l}\text { Plays a suppressive role in the } \\
\text { pathogenesis of hemangioma. } \\
\text { Inhibits ECs proliferation and } \\
\text { promotes ECs apoptosis }\end{array}$ & $\begin{array}{l}\text { Fei et al., } \\
2018\end{array}$ \\
\hline Hemangioma & miR-143 & Up & $B c l-2$ & Ex vivo & $\begin{array}{l}\text { Plays a suppressive role in the } \\
\text { pathogenesis of hemangioma. } \\
\text { Inhibits ECs proliferation and } \\
\text { promotes ECs apoptosis }\end{array}$ & $\begin{array}{l}\text { Huang et al., } \\
2017 \mathrm{a}\end{array}$ \\
\hline HHT & $\begin{array}{l}\operatorname{miR}-28-5 p \text { and } \\
\text { miR-361-3p }\end{array}$ & Down & $I G F-1$ & Ex vivo & Anti-angiogenic role in ECs & $\begin{array}{l}\text { Cannavicci et } \\
\text { al., } 2019\end{array}$ \\
\hline HHT & miR-205 & Down & $T G F-b$ & In vitro & $\begin{array}{l}\text { Anti-angiogenic role in ECs. } \\
\text { Inhibits proliferation, migration, } \\
\text { and tube formation }\end{array}$ & $\begin{array}{l}\text { Tabruyn et } \\
\text { al., } 2013\end{array}$ \\
\hline VM & miR-145 & Down & $T G F-b$ & In vitro & $\begin{array}{l}\text { Involved in the formation of } \\
\text { disorganized vessels in VM }\end{array}$ & $\begin{array}{l}\text { Xia et al., } \\
2017\end{array}$ \\
\hline $\mathrm{CCM}$ & $\begin{array}{l}\text { let-7b-5p, } \\
\text { miR-361-5p, } \\
\text { miR-370-3p, } \\
\text { miR-181a-2-3p, } \\
\text { and miR-95-3p }\end{array}$ & Down & $\begin{array}{l}M I B 1, H I F 1 A, P D C D 10, \\
T J P 1, O C L N, H E S 1, M A P K 1, \\
V E G F-A, E G F L-7, N F 1 \text {, and } \\
\text { ENG }\end{array}$ & $\begin{array}{l}\text { In vitro and in } \\
\text { silico }\end{array}$ & $\begin{array}{l}\text { Candidate miRNAs crucial for } \\
\text { CCM pathology }\end{array}$ & $\begin{array}{l}\text { Kar et al., } \\
2017\end{array}$ \\
\hline BAVM & miR-18a & Up & $V E G F-A$ and $V E G F-D$ & In vitro & $\begin{array}{l}\text { Anti-angiogenic role in in brain } \\
\text { AVM-ECs }\end{array}$ & $\begin{array}{l}\text { Ferreira et al., } \\
2014 \mathrm{a}\end{array}$ \\
\hline BAVM & miR-18a & Up & TSP-1 and VEGF-A & In vivo & $\begin{array}{l}\text { Anti-angiogenic role in in brain } \\
\text { AVM-ECs }\end{array}$ & $\begin{array}{l}\text { Ferreira et al., } \\
2014 \mathrm{~b}\end{array}$ \\
\hline BAVM & miR-18a & Up & $\begin{array}{l}M M P-2, A D A M 10, P A I-1, \\
B M P 4 \text { and HIF1A }\end{array}$ & $\begin{array}{l}\text { In vitro and in } \\
\text { vivo }\end{array}$ & $\begin{array}{l}\text { Plays a suppressive role in the } \\
\text { pathogenesis of BAVM. Anti- } \\
\text { angiogenic role in in brain AVM- } \\
\text { ECs }\end{array}$ & $\begin{array}{l}\text { Marín- } \\
\text { Ramos et al., } \\
2020\end{array}$ \\
\hline BAVM & $\begin{array}{l}\text { miR-195 } \\
\text { and miR-137 }\end{array}$ & Up & $\begin{array}{l}\text { VEGF, PI3K/Akt, MAPK/ } \\
\text { ERK and P38 }\end{array}$ & $\begin{array}{l}\text { In vitro and in } \\
\text { vivo }\end{array}$ & $\begin{array}{l}\text { Reduce brain AVM-VSMCs } \\
\text { migration, tube formation, and } \\
\text { survival }\end{array}$ & $\begin{array}{l}\text { Huang et al., } \\
\text { 2017b }\end{array}$ \\
\hline
\end{tabular}

Abbreviations: miR, MicroRNA; ECs, Endothelial cells; HHT, Hereditary haemorrhagic telangiectasia; VM, Venous malformation; CCM, Cerebral cavernous malformation; PTEN, Phosphatase and Tensin Homolog deleted on Chromosome 10; PI3K, Phosphoinositide 3-kinases; AKT, Protein kinase B alpha; VEGFR-2, Vascular endothelial growth factor receptor 2; Bcl-2, B-cell lymphoma 2; IGF-1, Insulin-like growth factor type-1; TGF- $b$, Transforming growth factor beta; MIB1, Mindbomb E3 Ubiquitin Protein Ligase 1; HIF1A, Hypoxia-inducible factor 1-alpha; PDCD10, Programmed Cell Death 10; TJP1, Tight Junction Protein 1; OCLN, Occludin; HES1, Hes Family BHLH Transcription Factor 1; MAPK1, Mitogen-activated protein kinase 1; VEGF-A, Vascular endothelial growth factor A; EGFL-7, EGF-like domain-containing protein; NF1, Neurofibromin 1; ENG, Endoglin; BAVM, Brain arteriovenous malformation; VEGF-D, Vascular endothelial growth factor-D; TSP-1, Thrombospondin 1; MMP-2, Matrix metalloproteinase-2; ADAM10, A Disintegrin and metalloproteinase domain-containing protein 10; PAI-1, Plasminogen activator inhibitor-1; BMP4, Bone morphogenetic protein 4; ERK, Extracellular signal-regulated kinase.

wall cell coverage, and impaired expression of the apolipoprotein (apoAV) gene are associated with Smad4deficient blood vessels. Therefore, evidence was presented that the loss of SMAD4 causes a decrease in the expression of vascular endothelial growth factor receptor 2 (VEGFR-2) and that the loss of a single VEGFR-2 allele in the null background of SMAD4 leads to an increase in the severity of AVM. Expression of NOTCH signaling components that are associated with arterial identity, as well as genes associated with venous and end cell identity, is impaired in the absence of SMAD4 (Crist et al., 2018).
TGF- $\beta$ signaling is critical to our development and a large family of molecules (Nickel et al., 2018). Incorrect TGF- $\beta$ signaling and BMP signaling through the known molecule dependence of the TGF- $\beta$ pathway are associated with vascular pathologies that can lead to AVM formation (Malik et al., 1998). Animal models of the activin a receptor like type $1(A C V R L 1)$ and endoglin $(E N G)$ mutations were created, which showed unusual TGF- $\beta$ signaling contributing to the induction of HHT induction, such as vascular fragility, hemorrhage, and the production of agedependent AVM. Endothelial cell-specific deletion of 
SMAD4 does not cause AVM but can cause fragility of blood vessels, as well as increase proliferation of endothelial cells and impair pericyte recruitment (Atri et al., 2014).

Disturbances in endothelial signaling contribute to the development of arteriovenous malformations, and the NOTCH and TGF- $\beta$ pathways appear to be particularly important for the development of these lesions. Abnormal activation or inactivation of NOTCH1 and NOTCH4 receptors, as well as their delta-like protein 4 (DLL4), implicates these molecules in the regulation of endothelial cell identity and branching morphogenesis (Fang and Hirschi, 2019; Mack and Iruela-Arispe, 2018). Elements of the TGF- $\beta$ pathway are involved in a similar way, but by a different mechanism. These genes appear to be critical for the regulation of vascular smooth muscle development and remodeling, especially in response to angiogenic stressors. It is possible that AVM represents abnormal signaling in these pathways along these pathways (Atri et al., 2014).

Currently, there is no doubt that an important role in the development and pathogenesis of cerebrovascular diseases play miRNAs. A number of candidate genes are known to be involved in the pathogenesis of brain AVMs, but at the same time, the influence of epigenetic factors that regulate the expression of target genes is of great importance in the development and progression of AVMs, including regulation of gene expression at the transcriptional or posttranscriptional levels with the participation of miRNAs. For instance, $R A S / T G F-\beta 1$ signaling is linked with miR-143/145 cluster regulation and various feedback and feed-forward loops. TGF- $\beta 1$ increases miR-143 expression, but miR-143 normally represses KRAS (Kent et al., 2014). The presence of RAS activating mutations was found by Nikolaev et al. (2018) and by Al-Olabi et al. (2018) however, has been found to repress miR-143/145 cluster expression. MiR143 also has a negative feedback effect on TGF- $\beta 1$ signaling normally, but the presence of $R A S$ activating mutations in in AVM-derived brain endothelial cells (brain AVM-ECs) would repress miR-143, and hence increase TGF- $\beta 1$ signals (Kent et al., 2014). Tab. 2 shows the miRNAs involved in vascular function and pathology that could potentially be involved in the pathogenesis of brain AVM through their binding with the 3-'UTRs mRNA of genes listed in this chapter (Du et al., 2015; Anand et al., 2010; Sun et al., 2019; Ruan et al., 2017; Davis et al., 2008; Liu et al., 2018; Biyashev et al., 2012; Bridge et al., 2012; Alhasan, 2019)

\section{MiR-18a}

Several studies have revealed that miR-18a is involved in in various physiological and pathological processes (Shen et al., 2019). However, the role of miR-18a in brain AVMs pathogenesis is currently unknown. A study by Ferreira et al. (2014b) showed that the expression of miR-18a was reduced in brain AVM-ECs compared with normal control brain endothelial cells (ECs). The authors also demonstrated that vascular endothelial growth factor-A (VEGF-A) and vascular endothelial growth factor-D (VEGF-D), as key lymphangiogenic and pro-angiogenic factors, showed increased expression in the brain AVM-ECs. The using of
miR-18a mimic significantly reduced the expression of $V E G F-A$ and VEGF-D in brain AVM-ECs. In addition, their study has shown that the strongest effects of miR-18a mimic were on cells subjected to arterial flow. These results demonstrated that miR-18a has antiangiogenic activity in brain AVM-ECs. Ultimately, the use of miR-18a can be further developed to improve brain AVMs treatment. In their further research, Ferreira et al. (2014a) showed that brain AVM-ECs secrete RNA-binding protein Argonaute-2 (Ago-2), which serves as a carrier for miR-18a and mediates, in part, miR-18a specific entry into brain ECs. Furthermore, the combination of miR-18a and Ago-2 (miR18a-Ago-2 complex) is active in vivo and can modulate the expression of angiogenic factors in blood samples, such as Thrombospondin 1 (TSP-1) and VEGF-A, thereby demonstrating that intravascular delivery of miRNA to the brain vasculature. The use of miR-18a-Ago-2 complex significantly increased the expression of TSP-1 and reduced the expression of $V E G F-A$ to levels comparable to healthy animals. A single administration of miR-18a mimic also showed an antiangiogenic effect. However, this may be due to the presence of existing circulating Ago-2 in the bloodstream, which led to their interaction. However, it should be noted that single miRNAs can be degraded by nucleases and can cause some concerns $(80 \%$ in less than $24 \mathrm{~h}$ ) for their successful delivery to the central nervous system (Ferreira et al., 2014a). Furthermore, most circulating miRNAs, including miR-18a, are stable in blood via binding the Ago2-2 protein (Arroyo et al., 2011). Moreover, miR-18a delivered by Ago-2 is functionally active both in vitro and in vivo. Thus, Ago-2 can be used as an effective carrier for miR-18a and the development of potential treatments for brain AVMs.

In a recent study by Marín-Ramos et al. (2020) identified signaling pathways involved in the normalization of the phenotype and function of brain AVM-ECs caused by miR18a. The authors show that the expression levels of the proangiogenic factor plasminogen activator inhibitor-1 (PAI-1) were higher in brain AVM-ECs than in control ECs and normalized by miR-18a. It is known that increased regulation of $P A I-1$ is considered a negative prognostic factor in various types of tumors due to its effect on neovascularization and migration of tumor cells (Takayama et al., 2016). These results are consistent with previously published data showing that PAI-1 induces VEGF expression and secretion (Peterle et al., 2018). An inverse correlation has also been described for PAI-1 and TSP-1 in clear cell renal cell carcinoma, where $P A I-1$ promotes angiogenesis (Zubac et al., 2010). In addition, it was shown that the use of miR-18a mimics leads to a decrease in the expression of PAI-1 and VEGF. They also showed that with an increase in miR-18a expression, the invasiveness of brain AVM-ECs decreases, which statistically significantly correlates with the suppression of the expression of matrix metalloproteinase-2 (MMP-2) and a disintegrin and metalloproteinase domain-containing protein 10 (ADAM10), but not for matrix metalloproteinase-9 (MMP-9). At the same time, they found that a single dose of miR-18a mimic might not be enough to cause a significant $(P>0.05)$ decrease in protein levels. In other words, it would be 
TABLE 2

MiRNAs and their target genes involved in vascular function and pathology

\begin{tabular}{|c|c|c|c|c|c|}
\hline miRNAs & Targets & $\begin{array}{l}\text { miRNAs } \\
\text { regulation }\end{array}$ & $\begin{array}{l}\text { Experimental } \\
\text { model }\end{array}$ & Functions & References \\
\hline miR-182 & RASA1 & Up & In vitro & $\begin{array}{l}\text { Promotes angiogenesis in } \\
\text { hepatocellular carcinoma }\end{array}$ & Du et al., 2015 \\
\hline miR-132 & RASA1 & Up & $\begin{array}{l}\text { In vivo and in } \\
\text { vivo }\end{array}$ & $\begin{array}{l}\text { Promotes angiogenesis in breast } \\
\text { cancer }\end{array}$ & $\begin{array}{l}\text { Anand et al., } \\
2010\end{array}$ \\
\hline miR-190 & $\begin{array}{l}\text { AKT-ERK signaling pathway via } \\
\text { STC2 }\end{array}$ & Up & $\begin{array}{l}\text { In vivo and in } \\
\text { vivo }\end{array}$ & $\begin{array}{l}\text { Anti-angiogenic effect in breast } \\
\text { cancer }\end{array}$ & Sun et al., 2019 \\
\hline miR-26b-5p & TGF- $\beta / S M A D 4$ & Down & In vitro & $\begin{array}{l}\text { Regulates hypoxia-induced } \\
\text { phenotypic switching of VSMCs }\end{array}$ & Ruan et al., 2017 \\
\hline $\operatorname{miR}-21$ & $\begin{array}{l}\text { SMAD4, TGF- } \beta / \text { BMP signaling } \\
\text { pathway }\end{array}$ & Up & In vitro & Control of the VSMCs phenotype & Davis et al., 2008 \\
\hline miR-137 & NOTCH signaling pathway & Up & $\begin{array}{l}\text { In vivo and in } \\
\text { vivo }\end{array}$ & $\begin{array}{l}\text { Promotes endothelial progenitor } \\
\text { cell proliferation and } \\
\text { angiogenesis in cerebral ischemic } \\
\text { stroke }\end{array}$ & Liu et al., 2018 \\
\hline $\operatorname{miR}-27 b$ & DLL4 & Up & In vitro & $\begin{array}{l}\text { Control of endothelial tip cell } \\
\text { fate, branching, and venous } \\
\text { specification }\end{array}$ & $\begin{array}{l}\text { Biyashev et al., } \\
2012\end{array}$ \\
\hline $\begin{array}{l}\operatorname{miR}-30 b \\
\text { and } \\
\text { miR-30c }\end{array}$ & DLL4 & Up & $\begin{array}{l}\text { In vivo and in } \\
\text { vivo }\end{array}$ & $\begin{array}{l}\text { Modulate ECs behavior during } \\
\text { angiogenesis }\end{array}$ & $\begin{array}{l}\text { Bridge et al., } \\
2012\end{array}$ \\
\hline $\mathrm{miR}-126$ & $V E G F-A$ & Up & In vitro & $\begin{array}{l}\text { Promotes angiogenesis in breast } \\
\text { cancer }\end{array}$ & Alhasan, 2019 \\
\hline
\end{tabular}

Abbreviations: miR, MicroRNA; ECs, Endothelial cells; VSMCs, Vascular smooth muscle cells; RASA1, RAS P21 protein activator 1; AKT, Protein kinase B alpha; ERK, Signal-regulated kinase; STC2, Stanniocalcin 2; TGF- $\beta$, Transforming growth factor beta; BMP, Bone morphogenetic protein; SMAD4, Mothers against decapentaplegic homolog 4; DLL4, Delta-like 4; VEGF-A, Vascular endothelial growth factor A.

interesting to study this in the long term with long-term use of miR-18a mimic and at higher doses. However, the main find in the study of Marín-Ramos et al. (2020) was that miR-18a inhibits bone morphogenetic protein 4 (BMP4) and hypoxia inducible factor 1 subunit alpha (HIF1-A). The direct binding between vascular disease and BMP4 and HIF1-A has been demonstrated in literature by the other authors. For instance, recent studies demonstrated that ECs are a significant source of BMP4 (Corriere et al., 2008). BMP4 is known to regulate physiological and pathological functions, including cardiovascular development, neovascularization in bone and tumors (Corriere et al., 2008). HIF-1A regulates cell-type-specific proangiogenic factors and cytokines either directly or indirectly. HIF-1A pathway regulates the activation of many proangiogenic factors in tumors and may promote metastasis (Cortes et al., 2019). In this context, MarínRamos et al. (2020) suggest that miR-18a can inhibit the development of brain AVM by blocking the expression of $B M P 4$ and HIF-1A, where both factors are overexpressed in the brain AVM-ECs, and that this relationship can be used to treat or prevent brain AVMs.

\section{MiR-195 and miR-137}

Vascular smooth muscle cells (VSMCs) play an important role in establishing the structure of the walls of normal vessels.
Multiple miRNAs are found to be responsible for VSMCs differentiation and proliferation under the pathological condition such as atherosclerosis and arterial hypertension (Leong et al., 2015). In addition, deregulation of phenotype switching is associated with brain AVMs. Some studies have shown that VSMCs can synthesize and secrete Insulin-like growth factor-binding protein-5 (IGFBP-5), and IGFBP-5 was found to be a nuclear protein and promoted cell proliferation and migration of VSMCs (Ha et al., 2015; Lee et al., 2013). Pan et al. (2017) established a functional connection between miR-137 and IGFBP-5 expression in VSMCs, demonstrating that IGFBP-5 is directly suppressed by miR-137, which suppresses the cell proliferation and migration in vitro.

Ha et al. showed that miR-137 and miR-195 are underexpressed in human brain AVM- VSMCs (Ha et al., 2015). To investigate the functional significance of this finding, the authors transfected brain AVM-VSMCs with miR-137 and miR-195 mimics and inhibitors. Mimics of both miR-137 and miR-195 reduced brain AVM-VSMCs migration, tube formation, and survival. Furthermore, miR-137 and miR-195 inhibited brain AVM-VSMCs vasculogenesis in vivo. In addition, miR-137- and miR-195-linked regulatory networks predicted by Ingenuity pathway analysis (IPA) involved mediators of signaling including VEGF, PI3K/Akt, MAPK/ERK and $P 38$, which are prominently implicated in vascular development. 


\section{Circulating miRNAs and Brain AVMs}

The expression profiles of circulating miRNAs in biofluids can reflect pathological changes in the body. Circulating miRNAs have suitable biological and physicochemical properties to be useful as novel biomarkers in clinical practice: (1) circulating miRNAs are highly stable and have a long half-life in the biofluids; (2) appear as a non-invasive detection method; (3) circulating miRNAs are highly sensitive to pathology; (4) circulating miRNAs can be detected in the early stages of the disease, whilst protein biomarkers are found in the blood circulation only when a significant part of the tissue damage has already occurred; (5) changing the expression profile of certain circulating miRNAs allows the detection of brain AVMs associated with a high risk of rupture; (6) circulating miRNAs can be efficiently quantified and also efficiently and relatively quickly evaluated in a modern laboratory with high sensitivity and specificity using quantitative real-time polymerase chain reaction (qRTPCR); and (7) circulating miRNAs can be used as a promising tool for faster and more accurate diagnosis of stroke subtypes (Fung et al., 2019; Kim et al., 2017; Wang et al., 2018). Circulating miRNAs can be used as biomarkers in various disease, including vascular anomalies (Chen et al., 2018; Liu et al., 2019; Pavlidis et al., 2018; Strub et al., 2016; Zhang et al., 2013). Tab. 3 summarizes all described circulating miRNAs that may be used as potential noninvasive biomarkers for vascular anomalies (Fei et al., 2018; Zhang et al., 2013; Chen et al., 2018; Strub et al., 2016; Liu et al., 2019; Pavlidis et al., 2018).

In turn, miRNAs can be exported from cells into biological fluids as part of extracellular vesicles (active secretion through exosomes and microvesicles) and be associated with ribonucleoproteins, particularly with Argonaute 2 proteins (miRNA-Ago2 complex). MiRNAs are also found in apoptotic bodies and are associated with lipoproteins (Fig. 2).

However, advances in the field of dysregulated circulating miRNAs in brain AVMs are still sparse. Using a next-generation sequencing (NGS) approach, Chen et al. (2018) performed profiling of circulating miRNAs in peripheral blood between three patients with unruptured brain AVMs and three controls. NGS detected 246 differentially expressed miRNAs. The authors further performed miRNA-mRNA co-expression network analysis (Gene ontology (GO) and Kyoto Encyclopedia of Genes and Genomes (KEGG)) and the co-expression networks were represented in VEGF signaling pathway (VEGF-A and kinase insert domain receptor $(K D R))$. In the network, the top three miRNAs which regulated the most target genes were hsa-miR-7-5p, hsa-miR-199a-5p and hsa-miR-200b-3p. Furthermore, these three circulating miRNAs and two target genes (VEGF- $A$ and $K D R$ ) were confirmed by qRT-PCR. Based on the qRT-PCR validation, three circulating miRNAs (let-7b-3p, miR-200b-3p and miR-199a-5p) were upregulated in brain AVMs. Moreover, VEGF-A and KDR were significantly upregulated in brain AVMs compared with normal samples. Taken together, this study identified a circulating miRNAs expression signature in peripheral blood of patients with brain AVMs, and the targeted pathway of VEGF signaling may have a crucial role in formation of brain AVMs. In addition, suggested that these three circulating miRNAs (miR-7-5p, miR-199a-5p and miR200b-3p) may serve as the potential diagnostic biomarkers.

The diagnosis of brain AVMs is currently based on imaging techniques such as computed tomography (CT) and/or magnetic resonance tomography (MRT). In contrast

TABLE 3

Circulating miRNAs as potential non-invasive biomarkers for vascular anomalies

\begin{tabular}{|c|c|c|c|c|c|}
\hline Disease & miRNA & Sample & $\begin{array}{l}\text { miRNAs } \\
\text { regulation }\end{array}$ & Platforms & References \\
\hline HHT & $\begin{array}{l}\operatorname{miR}-27 a \\
\operatorname{miR}-205\end{array}$ & Plasma & $\begin{array}{l}\text { Up } \\
\text { Down }\end{array}$ & qRT-PCR & Fei et al., 2018 \\
\hline HHT with PAVM & $\mathrm{miR}-210$ & Plasma & Up & $\begin{array}{l}\text { Microarray, } \\
\text { qRT-PCR }\end{array}$ & Zhang et al., 2013 \\
\hline PAVM & $\begin{array}{l}\text { miR-7e, miR-10a and } \\
\text { miR-193a-5p }\end{array}$ & Plasma & Down & Microarray & Zhang et al., 2013 \\
\hline PAVM & $\begin{array}{l}\text { miR-34a, miR-210, miR-214, } \\
\text { miR-486-3p and miR-486-5p }\end{array}$ & Plasma & Up & Microarray & Zhang et al., 2013 \\
\hline BAVM & $\begin{array}{l}\operatorname{miR}-7-5 p, \operatorname{miR}-199 a-5 p \text { and } \\
\text { miR-200b-3p }\end{array}$ & Whole blood & Up & NGS, qRT-PCR & Chen et al., 2018 \\
\hline $\begin{array}{l}\text { Hemangioma (before propranolol } \\
\text { treatment) } \\
\text { Hemangioma (after propranolol } \\
\text { treatment) }\end{array}$ & $\begin{array}{l}\text { C19MC } \\
\text { miRNA cluster }\end{array}$ & Plasma & $\begin{array}{l}\text { Up } \\
\text { Down }\end{array}$ & qRT-PCR & Strub et al., 2016 \\
\hline Hemangioma & miR-187-3p & Plasma & Down & qRT-PCR & Liu et al., 2019 \\
\hline Hemangioma & $\operatorname{miR}-126$ & Urine & Up & qRT-PCR & Pavlidis et al., 2018 \\
\hline
\end{tabular}

Abbreviations: miR, MicroRNA; HHT, Hereditary hemorrhagic telangiectasia; PAVM, Pulmonary arteriovenous malformation; BAVM, Brain arteriovenous malformation; qRT-PCR, real-time reverse transcription-PCR; NGS, Next-generation sequencing; C19MC miRNA cluster, miR-517a-3p, miR-517c-3p, miR$518 \mathrm{~b}, \mathrm{miR}-519 \mathrm{a}-3 \mathrm{p}$, and miR-520c-3p. 


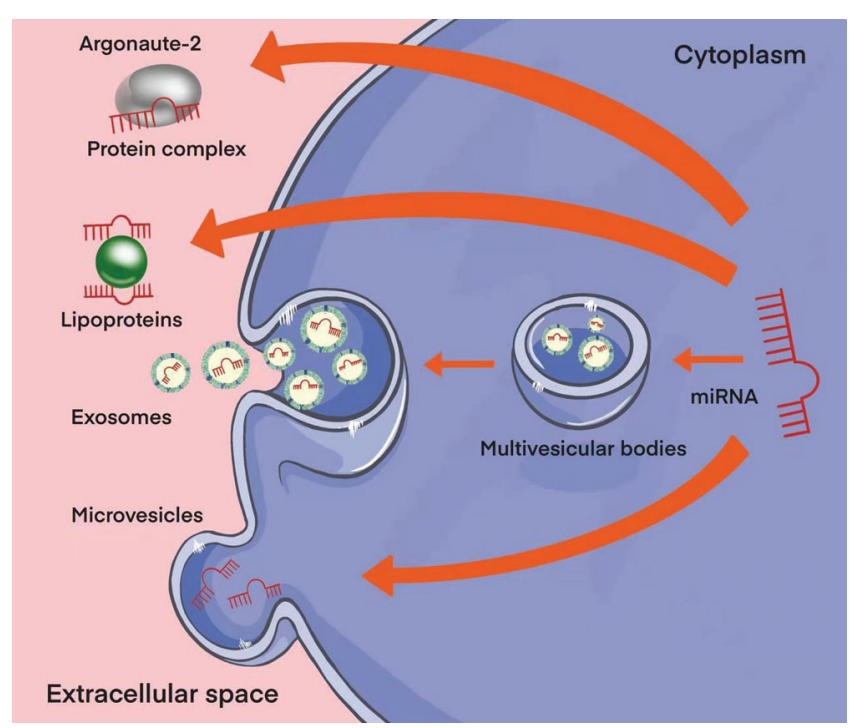

FIGURE 2. Types of circulating miRNAs. There are two major populations of circulating miRNAs, vesicle-associated (exosomes and microvesicles) and non-vesicle-associated (miRNA-Argonaute 2 complex and lipoproteins).

to tumors, which have many specific and non-specific plasma or serum biomarkers that can be used both for diagnosis, prognosis, and monitoring of therapy, there are no established non-invasive biomarkers for patients with brain AVMs (Vaidyanathan et al., 2019). The inefficiency of screening using CT and/or MRT to identify all individuals with a high risk of rupture of brain AVMs underscores the need for new screening methods to detect brain AVMs with a high risk of hemorrhage. Therefore, the specific circulating miRNAs expression profile represents as a mark of a pathophysiological or diseased condition. The well understanding of the brain AVMs and its process-specific miRNAs and the regulatory mechanisms of the miRNAs will lead to the clarification of the roles of circulating miRNAs, which may provide a promising screening tool for the faster diagnosis and more accurate prediction of hemorrhage. Unfortunately, to date, there are no studies that have studied the correlation between changes in the expression of circulating miRNAs and rupture of brain AVM vessels. However, there are a number of studies with cerebral aneurysms, where directly circulating miRNAs were used as prognostic biomarkers of rupture. A recent study has shown that circulating miR-21 may provide diagnostic clues for cerebral aneurysm rupture and guide clinical intervention (Jin et al., 2020). For instance, in one of 4 study groups, a group of patients with aneurysm with daughter aneurysm group (relatively high-rupture risk group) had extremely low levels of circulating miR-21 expression in serum, which may lead to the development of a hypothesis that miR-21 may have a protective effect on the vascular wall and a warning function of aneurysm rupture. Alternatively, in another study, Supriya et al. (2020) determined the plasma miRNA signature of ruptured cerebral aneurysms and identified 8 candidate circulating miRNAs (3 upregulated-miR-15a-5p, miR-34a-5p and miR374a-5p; 5 downregulated-miR-146a-5p, miR-376c-3p, miR18b-5p, miR-24-3p and miR-27b-3p) that could be useful predictive biomarkers for this condition. At present, preventive medicine is very important. Therefore, the development of new biomarkers in the person of circulating miRNAs in brain AVMs can help to recognize the possible risk of rupture and hemorrhage and take certain therapeutic tactics.

\section{Conclusion}

In the vascular system, miRNAs regulate endothelial responses to shear stress and endothelial-smooth muscle cell interactions, and dysregulation of miRNAs may contribute to pathologic processes, including vascular anomalies. However, little is known about the role of miRNAs in the genesis and progression of brain AVMs. Only a few studies attempted to correlate changes in the expression levels of miRNAs and their gene targets with brain AVMs in vitro and in vivo, in order to elucidate the mechanisms of pathogenesis. The results of these studies allow a better understanding of the processes associated with the formation and rupture of brain AVMs. In addition, we suggested that circulating miRNAs would function as novel non-invasive biomarkers for brain AVMs, but which still needs further research.

Ethical Approval: This article does not contain any studies with human participants performed by any of the authors.

Author Contributions: IG: Conceptualization, Writingoriginal draft, Writing-review \& editing and Supervision; OB: Investigation, Validation and Data curation; CW, AS, YL, HX, CL, XX, YG: Data curation; GY: Funding acquisition.

Funding Statement: This work was supported by National Natural Science Foundations of China (81971135); Natural Science Foundations of Heilongjiang (YQ2020H014); "Chunhui Plan" of Ministry of Education (HLJ2019009); Distinguished Young Foundations of the First Affiliated Hospital of Harbin Medical University (HYD2020JQ0014); The reported study was funded by RFBR and NSFC, Project No. 21-515-53017.

Conflicts of Interest: The authors declare they have no conflict of interest.

\section{References}

Alhasan L (2019). MiR-126 modulates angiogenesis in breast cancer by targeting VEGF-A-mRNA. Asian Pacific Journal of Cancer Prevention 20: 193.

Anand S, Majeti BK, Acevedo LM, Murphy EA, Mukthavaram R et al. (2010). MicroRNA-132-mediated loss of p120RasGAP activates the endothelium to facilitate pathological angiogenesis. Nature Medicine 16: 909-914.

Arroyo JD, Chevillet JR, Kroh EM, Ruf IK, Pritchard CC et al. (2011). Argonaute2 complexes carry a population of circulating microRNAs independent of vesicles in human plasma. Proceedings of the National Academy of Sciences of the United States of America 108: 5003-5008.

Atri D, Larrivée B, Eichmann A, Simons M (2014). Endothelial signaling and the molecular basis of arteriovenous malformation. Cellular and Molecular Life Sciences 71: 867-883.

Al-Olabi L, Polubothu S, Dowsett K, Andrews KA, Stadnik P et al. (2018). Mosaic RAS/MAPK variants cause sporadic 
vascular malformations which respond to targeted therapy. Journal of Clinical Investigation 128: 1496-1508.

Biyashev D, Veliceasa D, Topczewski J, Topczewska JM, Mizgirev I et al. (2012). miR-27b controls venous specification and tip cell fate. Blood, The Journal of the American Society of Hematology 119: 2679-2687.

Bridge G, Monteiro R, Henderson S, Emuss V, Lagos D et al. (2012). The microRNA-30 family targets DLL4 to modulate endothelial cell behavior during angiogenesis. Blood 120: 5063-5072.

Can A, Gross BA, Du R (2017). The natural history of cerebral arteriovenous malformations. Handbook of Clinical Neurology 143: 15-24. DOI 10.1016/B978-0-444-63640-9.00002-3.

Cannavicci A, Zhang Q, Dai SC, Faughnan ME, Kutryk MJ (2019). Decreased levels of miR-28-5p and miR-361-3p and increased levels of insulin-like growth factor $1 \mathrm{mRNA}$ in mononuclear cells from patients with hereditary hemorrhagic telangiectasia. Canadian Journal of Physiology and Pharmacology 97: 562-569.

Correia de Sousa M, Gjorgjieva M, Dolicka D, Sobolewski C, Foti M (2019). Deciphering miRNAs' action through miRNA editing. International Journal of Molecular Sciences 20: 6249.

Corriere MA, Rogers CM, Eliason JL, Faulk J, Kume T et al. (2008). Endothelial Bmp4 is induced during arterial remodeling: Effects on smooth muscle cell migration and proliferation. Journal of Surgical Research 145: 142-149.

Cortes E, Lachowski D, Robinson B, Sarper M, Teppo JS et al. (2019). Tamoxifen mechanically reprograms the tumor microenvironment via HIF-1A and reduces cancer cell survival. EMBO Reports 20: e46557.

Crist AM, Lee AR, Patel NR, Westhoff DE, Meadows SM (2018). Vascular deficiency of Smad4 causes arteriovenous malformations: A mouse model of Hereditary Hemorrhagic Telangiectasia. Angiogenesis 21: 363-380.

Chen Y, Li Z, Shi Y, Huang G, Chen L et al. (2018). Deep sequencing of small RNAs in blood of patients with brain arteriovenous malformations. World Neurosurgery 115: e570-e579.

Dai Y, Wan Y, Qiu M, Wang S, Pan C et al. (2018). lncRNA MEG3 suppresses the tumorigenesis of hemangioma by sponging miR-494 and regulating PTEN/PI3K/AKT pathway. Cellular Physiology and Biochemistry 51: 2872-2886.

Davis BN, Hilyard AC, Lagna G, Hata A (2008). SMAD proteins control DROSHA-mediated microRNA maturation. Nature 454: $56-61$.

Du C, Weng X, Hu W, Lv Z, Xiao H et al. (2015). Hypoxia-inducible MiR-182 promotes angiogenesis by targeting RASAl in hepatocellular carcinoma. Journal of Experimental \& Clinical Cancer Research 34: 67.

Fang JS, Hirschi KK (2019). Molecular regulation of arteriovenous endothelial cell specification. F1000Research 8: F1000.

Fei Z, Qiu M, Qi X, Dai Y, Wang S et al. (2018). MicroRNA-424 suppresses the proliferation of hemangioma-derived endothelial cells by targeting VEGFR-2. Molecular Medicine Reports 18: 4065-4071.

Fereydooni A, Dardik A, Nassiri N (2019). Molecular changes associated with vascular malformations. Journal of Vascular Surgery 70: 314-326.

Ferreira R, Santos T, Amar A, Gong A, Chen TC et al. (2014a). Argonaute2 promotes miR-18a entry in human brain endothelial cells. Journal of the American Heart Association 3: e000968.

Ferreira R, Santos T, Amar A, Tahara SM, Chen TC et al. (2014b). MicroRNA-18a improves human cerebral arteriovenous malformation endothelial cell function. Stroke 45: 293-297.
Fung EC, Butt AN, Eastwood J, Swaminathan R, Sodi R (2019). Circulating microRNA in cardiovascular disease. Advances in Clinical Chemistry 91: 99-122.

Gallione CJ, Repetto GM, Legius E, Rustgi AK, Schelley SL et al. (2004). A combined syndrome of juvenile polyposis and hereditary haemorrhagic telangiectasia associated with mutations in MADH4 (SMAD4). Lancet 363: 852-859.

Gareev I, Beylerli O, Yang G, Sun J, Pavlov V et al. (2020). The current state of MiRNAs as biomarkers and therapeutic tools. Clinical and Experimental Medicine 20: 349-359.

Ha YM, Nam JO, Kang YJ (2015). Pitavastatin regulates Ang II induced proliferation and migration via IGFBP-5 in VSMC. The Korean Journal of Physiology \& Pharmacology: Official Journal of the Korean Physiological Society and the Korean Society of Pharmacology 19: 499.

Huang C, Huang J, Ma P, Yu G (2017a). microRNA-143 acts as a suppressor of hemangioma growth by targeting $\mathrm{Bcl}-2$. Gene 628: 211-217.

Huang J, Song J, Qu M, Wang Y, An Q et al. (2017b). Micro RNA-137 and micro RNA-195* inhibit vasculogenesis in brain arteriovenous malformations. Annals of Neurology 82: 371-384.

Jin H, Jiang Y, Liu X, Meng X, Li Y (2020). Cell-free microRNA-21: Biomarker for intracranial aneurysm rupture. Chinese Neurosurgical Journal 6: 15.

Kar S, Bali KK, Baisantry A, Geffers R, Samii A, Bertalanffy H (2017). Genome-wide sequencing reveals MicroRNAs downregulated in cerebral cavernous malformations. Journal of Molecular Neuroscience 61: 178-188.

Kim S-H, Weiß C, Hoffmann U, Borggrefe M, Behnes M, Akın I (2017). Advantages and limitations of current biomarker research. Current Pharmaceutical Biotechnology 18: 445-455.

Kent OA, McCall MN, Cornish TC, Halushka MK (2014). Lessons from miR-143/145: The importance of cell-type localization of miRNAs. Nucleic Acids Research 42: 7528-7538.

Lee DH, Kim JE, Kang YJ (2013). Insulin like growth factor binding protein-5 regulates excessive vascular smooth muscle cell proliferation in spontaneously hypertensive rats via ERK $1 / 2$ phosphorylation. The Korean Journal of Physiology \& Pharmacology: Official Journal of the Korean Physiological Society and the Korean Society of Pharmacology 17: 157.

Leong XF, Ng CY, Jaarin K (2015). Animal models in cardiovascular research: Hypertension and atherosclerosis. BioMed Research International 2015: 528757.

Liu C, Zhao Z, Ji Z, Jiang Y, Zheng J (2019). MiR-187-3p enhances propranolol sensitivity of hemangioma stem cells. Cell Structure and Function 44: 41-50.

Liu XL, Wang G, Song W, Yang WX, Hua J, Lyu L (2018). microRNA-137 promotes endothelial progenitor cell proliferation and angiogenesis in cerebral ischemic stroke mice by targeting NR4A2 through the Notch pathway. Journal of Cellular Physiology 233: 5255-5266.

Lu TX, Rothenberg ME (2018). MicroRNA. Journal of Allergy and Clinical Immunology 141: 1202-1207.

Mack JJ, Iruela-Arispe ML (2018). NOTCH regulation of the endothelial cell phenotype. Current Opinion in Hematology 25: 212.

Magro E, Gentric JC (2020). Brain AVM management: Anything new under the sun? Journal of Neuroradiology 47: 3-4.

Malik G, Abdulrauf S, Yang XY, Gutierrez JA, Rempel SA (1998). Expression of transforming growth factor- $\beta$ complex in arteriovenous malformations. Neurologia Medico-Chirurgica 38: 161-164. 
Marín-Ramos NI, Thein TZ, Ghaghada KB, Chen TC, Giannotta SL, Hofman FM (2020). miR-18a inhibits BMP4 and HIF-1a normalizing brain arteriovenous malformations. Circulation Research 127: e210-e231.

Michlewski G, Cáceres JF (2019). Post-transcriptional control of miRNA biogenesis. RNA 25: 1-16.

Murthy SB, Merkler AE, Omran SS, Gialdini G, Gusdon A et al. (2017). Outcomes after intracerebral hemorrhage from arteriovenous malformations. Neurology 88: 1882-1888.

Nickel J, Ten Dijke P, Mueller TD (2018). TGF- $\beta$ family co-receptor function and signaling. Acta Biochimica et Biophysica Sinica 50: 12-36.

Nikolaev SI, Vetiska S, Bonilla X, Boudreau E, Jauhiainen S et al. (2018). Somatic activating KRAS mutations in arteriovenous malformations of the brain. New England Journal of Medicine 378: 250-261.

Pan J, Li K, Huang W, Zhang X (2017). MiR-137 inhibited cell proliferation and migration of vascular smooth muscle cells via targeting IGFBP-5 and modulating the mTOR/STAT3 signaling. PLoS One 12: e0186245.

Park ES, Kim S, Huang S, Yoo JY, Körbelin J et al. (2021). Selective endothelial hyperactivation of oncogenic KRAS induces brain arteriovenous malformations in mice. Annals of Neurology 89: 926-941.

Pavlidis L, Spyropoulou GA, Papas A, Demiri E (2018). Urinary excretion of microRNA-126 is a biomarker for hemangioma proliferation. Plastic and Reconstructive Surgery 141: $319 \mathrm{e}-320 \mathrm{e}$.

Peterle GT, Maia LL, Trivilin LO, De Oliveira MM, Dos Santos JG et al. (2018). PAI-1, CAIX, and VEGFA expressions as prognosis markers in oral squamous cell carcinoma. Journal of Oral Pathology \& Medicine 47: 566-574.

Ruan C, Lu J, Wang H, Ge Z, Zhang C, Xu M (2017). miR-26b-5p regulates hypoxia-induced phenotypic switching of vascular smooth muscle cells via the TGF- $\beta / S \operatorname{mad} 4$ signaling pathway. Molecular Medicine Reports 15: 4185-4190.

Shen K, Cao Z, Zhu R, You L, Zhang T (2019). The dual functional role of MicroRNA-18a (miR-18a) in cancer development. Clinical and Translational Medicine 8: 32.

Sohel MMH (2020). Circulating microRNAs as biomarkers in cancer diagnosis. Life Sciences 248: 117473.

Strub GM, Kirsh AL, Whipple ME, Kuo WP, Keller RB et al. (2016). Endothelial and circulating C19MC microRNAs are biomarkers of infantile hemangioma. JCI Insight 1: e88856.
Sun G, Liu M, Han H (2019). Overexpression of microRNA-190 inhibits migration, invasion, epithelial-mesenchymal transition, and angiogenesis through suppression of protein kinase B-extracellular signal-regulated kinase signaling pathway via binding to stanniocalicin 2 in breast cancer. Journal of Cellular Physiology 234: 17824-17838.

Supriya M, Christopher R, Devi BI, Bhat DI, Shukla D (2020). Circulating microRNAs as potential molecular biomarkers for intracranial aneurysmal rupture. Molecular Diagnosis \& Therapy 24: 351-364.

Tabruyn SP, Hansen S, Ojeda-Fernández ML, Bovy N, Zarrabeitia R et al. (2013). MiR-205 is downregulated in hereditary hemorrhagic telangiectasia and impairs TGF-beta signaling pathways in endothelial cells. Angiogenesis 16: 877-887.

Takayama Y, Hattori N, Hamada H, Masuda T, Omori K et al. (2016). Inhibition of PAI-1 limits tumor angiogenesis regardless of angiogenic stimuli in malignant pleural mesothelioma. Cancer Research 76: 3285-3294.

Vaidyanathan R, Soon RH, Zhang P, Jiang K, Lim CT (2019). Cancer diagnosis: From tumor to liquid biopsy and beyond. Lab on a Chip 19: 11-34.

Wang H, Peng R, Wang J, Qin Z, Xue L (2018). Circulating microRNAs as potential cancer biomarkers: The advantage and disadvantage. Clinical Epigenetics 10: 59.

Wooderchak-Donahue W, Stevenson DA, McDonald J, Grimmer JF, Gedge F, Bayrak-Toydemir P (2012). RASA1 analysis: clinical and molecular findings in a series of consecutive cases. European Journal of Medical Genetics 55: 91-95. DOI 10.1016/j.ejmg.2011.11.008.

Xia HF, Ren JG, Zhu JY, Yu ZL, Zhang W et al. (2017). Downregulation of miR-145 in venous malformations: Its association with disorganized vessels and sclerotherapy. European Journal of Pharmaceutical Sciences 100: 126-131.

Zhang Q, Kandic I, Faughnan ME, Kutryk MJ (2013). Elevated circulating microRNA-210 levels in patients with hereditary hemorrhagic telangiectasia and pulmonary arteriovenous malformations: a potential new biomarker. Biomarkers 18: 23-29.

Zhang R, Zhu W, Su H (2016). Vascular integrity in the pathogenesis of brain arteriovenous malformation. In: Applegate R, Chen G, Feng H, Zhang J (eds.), Brain Edema XVI. Acta Neurochirurgica Supplement. Cham: Springer.

Zubac DP, Wentzel-Larsen T, Seidal T, Bostad L (2010). Type 1 plasminogen activator inhibitor (PAI-1) in clear cell renal cell carcinoma (CCRCC) and its impact on angiogenesis, progression and patient survival after radical nephrectomy. BMC Urology 10: 20. 